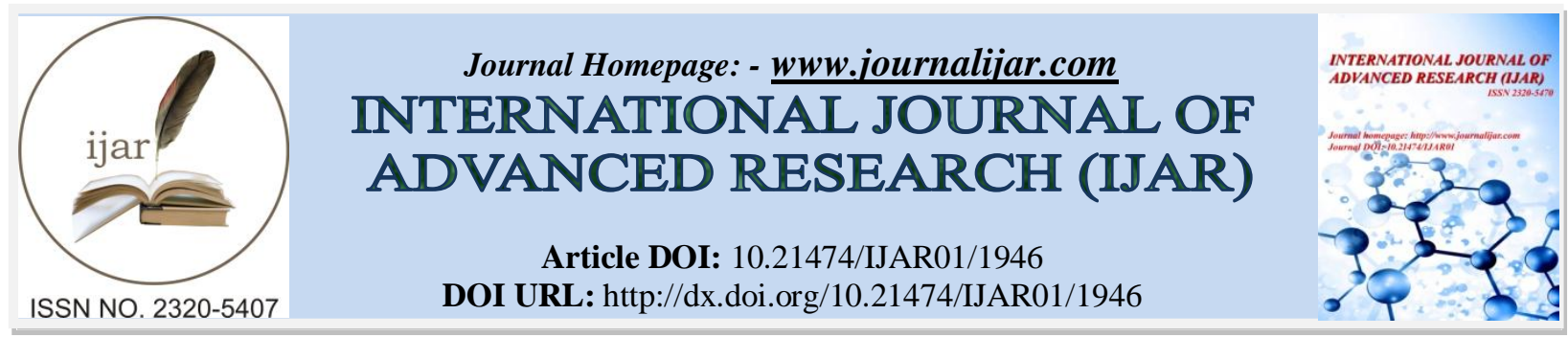

RESEARCH ARTICLE

\title{
REMODELLING OFHOSPITAL EQUIPMENT- INCORPORATING EXPERIENCE TO ADDRESS PATIENT COMFORT AND SAFETY.
}

Ranjitpal Singh Bhogal and Pankaj Arora.

\section{Manuscript Info}

Manuscript History

Received: 21 August 2016

Final Accepted: 22 September 2016

Published: October 2016

Key words:-

patient, comfort, safety, healthcare associated infection.

\section{Abstract}

Background and objectives:- Stretchers may not be the protagonist in a tertiary care hospital but occupies an important place in emergency department as many patients are kept on stretchers to accommodate more patients in the existing space. The purposes of this study was to identify problems related to traditional stretchers and modify its design to make it safe for patients, cost-efficient, user friendly for health care workers \& easy to maintain to reduce health care associated infections.

Methods:- Information about the existing problems faced with use of stretchers were discussed with the patients, health care workers handling stretchers and nurses of a tertiary care hospital. These were discussed with the Engineering students \& vendor. The prototype was made and initially 60 number stretchers were introduced in the hospital.

Results:- The problems identified in the traditional design were patients hands use to fell on the side which may have led to injury, difficulty in taking vital parameters especially blood pressure \& frequent breaking of the instruments, stretchers were made up of iron, coated with white paint that often become rusted, top was made up of metal that causes discomfort to patient, wheels of the stretchers used to bend \& break frequently that may have compromised patient safety and also hamper manoeuvring during transportation and aesthetically poor. The area of the stretchers was slightly increased, the frame was prepared with Stainless Steel 305 with increased thickness, swing type side rails with locks were provided and castor wheels were fitted instead of bicycle wheels. A mesh was also attached to the base of the stretchers to accommodate cylinders and patients luggage.

Interpretation \& Conclusion:- The new design is safer \& comfortable for patients, cost efficient to the hospital management and easier to handle to HCWs. However the retrieval of the stretchers and frequent breaking of the castor wheels are still issues that need attention. 


\section{Introduction:-}

Stretchers or trolleys may not be protagonist in a tertiary care hospital but certainly occupy an important place as many patients are kept on stretchers for hours and days in emergency department. This exercise is defined as boarding ${ }^{1}$ and may lead to increased morbidity and mortality with increased length of stayand the patient supported on stretcher may be at a higher risk of pressure and necrosis ${ }^{2}$. However, it is resorted to, due to overcrowding in emergency departments and consequently lack of beds,predominantly in public sector hospital. Additionally during disasters \& calamities there is hardly any alternative to it since the hospital beds are at premium.Stretchers, even though, useful have inherent disadvantages Vis a Vis beds. A study conducted on 60 subjects using conventional wood and canvas stretcher found them cold and uncomfortable, especially over the heels and lower back ${ }^{3}$. Adverse events may occur during ambulance stretcher operation and can result in significant injury to patients and ambulance personnel ${ }^{4}$. But stretchers have got some benefits over routine hospital bed also. A study conducted in Intensive care unit setting found stretchers to be better compared to hospital bed in conducting CPR as they do not require back board, which is essential when performing CPR on soft surface ${ }^{5}$. Research has proved that straddling chest compressions performed on a moving stretchers are as effective as on the floor. The time for transporting the patient to get advance life support may be reduced by performing straddling chest compression on stretchers, as the quality of chest compression performed on a moving stretcher was as effective as on the floor ${ }^{6}$.Despite the limitations of stretchers, their handling plays a vital part in the early management of seriously ill and injured patients. A lot of essential features have to be adopted so that it can be made safe for the patients, cost-efficient for the hospital management and easy to use and maintain for health care workers. The design of the stretcher may include following features:

- Interchangeable between the hospital and the ambulance.

- Washable

- Made up of antistatic material.

- $\quad$ Fitted with loops on either side.

- Ability to rise and fall to allow transference by sliding on to a standard X- Ray

- Carry Oxygen cylinder, drip stands, a tray for drainage bottles and other belongings of the patients.

\section{Case Report:-}

Ours is multi-speciality public sector tertiary care hospital with close to 2000 beds catering topatients from across the country. Atwo hundred bedded emergencycomplex with comprehensive life-saving medical services caters to all medical and surgical emergencies round the clock. Due to high and positive brand awareness among target audiences our hospital is overcrowded at any given time with more than 500 hundred patients admitted or under observation in the emergency complex. Patients are kept on stretchers to accommodate more patients in the existing space resulting in an unending requirement for stretchers in emergency complex of the institute.

\section{Some of the problems faced with old stretcher were:-}

1. Patient's hands use to fall on the side which may have led to injury.

2. Difficulty in taking vital parameters especially blood pressure due to lack of space to keep sphygmomanometer. It used to cause frequent breakdown of theinstrument.

3. Iron rods and sheet that make skeleton of the stretchers often become rusted over time and may increase the risk of health care associated infection.

4. Top was made up of metal that used to be hot in summers and very cold in winters.

5. Wheels of the stretchers used to bend and break frequently that again may have compromised patient safety.Broken wheels also hamper manoeuvring during transportation.

We therefore devised our own stretcher specificationssuitable to our need. The manufacturer was asked to develop the prototype with following specifications that were developed by the department of Hospital Administration. The difference from the BIS specifications can also be seen from reference.

Specifications-

\begin{tabular}{|c|c|c|c|c|}
\hline Specifications & \multicolumn{2}{|c|}{ Bureau of Indian Standard } & \multicolumn{2}{|c|}{ PGIMER Specifications } \\
\hline Length & \multicolumn{2}{|c|}{$1985 \mathrm{~mm} \pm 5 \mathrm{~mm}$} & \multicolumn{2}{|c|}{$2050 \mathrm{~mm} \pm 10 \mathrm{~mm}$} \\
\hline Width & \multicolumn{2}{|l|}{$519 \mathrm{~mm} \pm 10 \mathrm{~mm}$} & \multicolumn{2}{|l|}{$620 \mathrm{~mm} \pm 10 \mathrm{~mm}$} \\
\hline Height & \multicolumn{2}{|l|}{$619 \mathrm{~mm} \pm 10 \mathrm{~mm}$} & \multicolumn{2}{|l|}{$850 \mathrm{~mm} \pm 10 \mathrm{~mm}$} \\
\hline Frame Work & Thickness of Tube & Diameter of Pipe & Thickness of Tube & Diameter of Pipe \\
\hline Vertical Member & $1.02 \mathrm{~mm}$ & $31.75 \mathrm{~mm}$ & $1.5 \mathrm{~mm}$ & $31.75 \mathrm{~mm}$ \\
\hline
\end{tabular}




\begin{tabular}{|l|l|l|l|}
\hline Horizontal Member & $1.02 \mathrm{~mm}$ & $25.40 \mathrm{~mm}$ & $1.5 \mathrm{~mm}$ \\
\hline Removable stretcher & $\begin{array}{l}\text { Stainless steel } 0.8 \mathrm{~mm} \text { with } 100 \mathrm{~mm} \\
\text { length }\end{array}$ & $\begin{array}{l}\text { Removable stretcher made of Stainless sheet } \\
0.8 \mathrm{~mm} \text { thick. The sheet metal top shall be dished } \\
\text { to depth of 30mm in the centre with four number } \\
\text { legs of approximately 100mm length should be } \\
\text { placed to keep stretcher on ground or on flat table } \\
\text { top. }\end{array}$ \\
\hline Side railing & & $\begin{array}{l}\text { Swing type side stretchers with locks made of } \\
\text { same stainless steel shall be provided with the } \\
\text { stretchers. }\end{array}$ \\
\hline
\end{tabular}

\section{Discussion:-}

Stretchers occupy an important place in an overcrowded hospitals, toaccommodate more patients in the existing space. The purpose of this study was to identify problems related to traditional stretchers and modify its design to overcome them and make them user friendly. Information about the existing problems faced with use of stretchers were discussed with the patients, health care workers handling stretchers and nurses of the emergency department. The problems that were addressable were enlisted. These were discussed with the concerned engineers of the hospital\&a vendor. The prototype was made and initially 60 number stretchers were introduced in the hospital.

The area of the stretcher was increased. The frame was made with Stainless Steel 305 grade with increased thickness in horizontal and vertical frame. Swing type side rails with locks were provided to prevent patient fall and castor wheels were fitted instead of bicycle wheels. A mesh was also attached to the base of the stretcher to accommodate cylinders and patients' belongings. A fluid stand was also attached to hang the fluid bottles.

The stretchers of the same specifications have been adopted by two of regional tertiary care hospitals facing similar problem of overcrowding and difficulty in handling patients.However we are aware that the improvement is a continuous process. Due to the horizontal spread of the hospital, these stretchers are taken to vast distances over all types of surfaces. This leads to breakdown of castors which need to be addressed. Similarly these are left behind at all possible places. Their retrieval is an issue, therefore RFID may offer a solution but the practicability needs to be workedout. Theintent behind these were to procure stretcherswhich are comfortable for the patients. At the same time these are easier to maintain and economical in long term and has longer shelf time.

The case report sheds light on an essential hospital equipment which is generally overlooked.But the importance of the stretchers cannot be underestimated as far as the issues of hospital acquired infection, patient comfort and safety is concerned. This case report is not claiming hospital policy makers to adopt these specifications; but, they must be aware about subtle aspects of stretchers and other equipment's used in the hospital for patient care and tailor them as per their need.

\section{References:-}

1. Rabin E, Kocher K, McClelland M, Pines J, Hwang U, Rathlev N, et al. Solutions to emergency department "boarding" and crowding are underused and may need to be legislated. Health AffProj Hope 2012; 31:1757-66.

2. Lovell ME, Bradshaw P. Pressure effects from the military stretcher. J R Army Med Corps 1993; 139:98-9.

3. Lovell ME, Bradshaw P. Evaluation of the conventional stretcher as a support surface. Injury 1993; 24:660-1.

4. Weston PA, Goodhead TC. Transfer facilities for the seriously ill and injured. Injury 1980; 12:123-9.

5. Nishisaki A, Maltese MR, Niles DE, Sutton RM, Urbano J, Berg RA, et al. Backboards are important when chest compressions are provided on a soft mattress. Resuscitation 2012; 83:1013-20.

6. 6. Lei Z, Qing H, Yaxiong Z. The efficacy of straddling external chest compression on a moving stretcher. Resuscitation 2010; 81:1562-5. 